RESEARCH REPORT

\title{
Illness, disease, and sickness absence: an empirical test of differences between concepts of ill health
}

\author{
Anders Wikman, Staffan Marklund, Kristina Alexanderson
}

J Epidemiol Community Health 2005;59:450-454. doi: 10.1136/jech.2004.025346

See end of article for authors' affiliations

................

Correspondence to:

Dr A Wikman, Department

for Work and Health,

National Institute for

Working Life, 11391

Stockholm, Sweden;

anders.wikman@ali.se

Accepted for publication 18 January 2005

\begin{abstract}
Objectives: In studies of public health and morbidity different concepts of ill health are often seen as interchangeable alternatives. With the help of extensive population information this research intends to show how different concepts and measurements produce very different pictures of health and ill health. The concept trilogy of "illness," "disease," and "sickness" is used to capture different aspects of ill health.

Design: Cross sectional data were obtained through comprehensive interview surveys 1988-2001 and registers of sickness absence. Because of lack of data some years had to be excluded.

Settings: Swedish population.

Participants: Annual data for around 3500 employed and self employed persons.

Main results: Most people have some sort of illness or complaint. Fewer could be registered with a disease. Even fewer had been on sick leave. The overlap was fairly low. There also was an obvious discrepancy between reporting having a disease and a subject's rating of general health. It was shown that the different concepts showed different trends over time.

Conclusions: The discrepancies between the concepts imply that you have to be very careful when using public health data to illustrate different aspects of morbidity. The comparatively low degree of overlap between them shows that they represent different realities. There is a need to do further empirical research about how different aspects of morbidity are interrelated. Their lack of interrelation seems to be an important research area worth developing further.
\end{abstract}

l: n studies of public health and morbidity different concepts and measurements are used without taking into account their different origins and prerequisites. The measurements are often seen as interchangeable alternatives. Differences may be related to methodological context, for example because they are based on different sources of data (from registers or surveys), ${ }^{12}$ or on different informants (physicians or patients)..$^{3-5}$ There may also be differences in their theoretical context, concerning for example their focus (medical symptoms or social consequences for the person). ${ }^{6} 7$ These aspects have been discussed theoretically before, but few attempts have been made to empirically study the differences. Here we intend to deepen the discussion and use empirical data to show differences between different measures taken from the same population.

The concept trilogy of "illness," "disease," and "sickness," has been used to capture different aspects of ill health, and here we will apply the following, generally used, definitions of them. ${ }^{8-15}$ Illness is defined as the ill health the person identifies themselves with, often based on self reported mental or physical symptoms. In some cases this may mean only minor or temporary problems, but in other cases self reported illness might include severe health problems or acute suffering. ${ }^{16}$ It may include health conditions that limit the person's ability to lead a normal life. According to this definition illness is seen as a rather wide concept.

Disease, on the other hand, is defined as a condition that is diagnosed by a physician or other medical expert. Ideally, this would include a specific diagnosis according to standardised and systematic diagnostic codes. This would in most cases also mean that the specific condition has a known biomedical cause and often known treatments and cures. However, it should be mentioned that there are several limitations to this ideal in practice. One is the fact that a number of medical diagnoses have to be based on subjective information from the patient concerning pains and feelings. Another limitation is the fact that a number of diagnoses are based on syndromes and complex interrelations between different organ systems and thus are not always very specific.

Sickness is related to a different phenomenon, namely the social role a person with illness or sickness takes or is given in society, in different arenas of life. One type of data concerning a more limited aspect of sickness is that relating to sickness absence from work. Such data are often used to measure social consequences for the person of ill health. ${ }^{1}{ }^{1718}$ Here data on sickness absence will be used to measure sickness.

These three concepts are often thought to overlap (fig 1) in that a person who does not feel well, is diagnosed by a physician, and then, if the problems are serious and affect their ability to work, is sick listed. In reality, however, things are not this simple. In some forms of experienced illness the person never bothers to have the condition confirmed by a physician, either because the problem is too small or because there is not much help available. Some illnesses and diseases do not lead to sickness and most illnesses and diseases do not lead to sickness absence, either because they do not lead to a reduction in the work capacity needed, or the person may still choose to work, that is to be "sickness present". ${ }^{19}$

Apart from these three concepts, which seem to be related in a complex way, we have a fourth one-the concept of health. The concept of health has been defined and understood in many different ways. ${ }^{20}$ Often the term is used as the opposite of illness or disease, so that the more you have of illness or disease, the less you have of health and vice versa. In the past decade however, health has often been understood to belong to a completely different dimension from disease or illness and thus, not defined as their opposite. In this tradition various definitions of health are used, for instance health is defined as wellbeing, or as capacity to act to reach vital goals, or the possibility of experiencing meaningful life. 


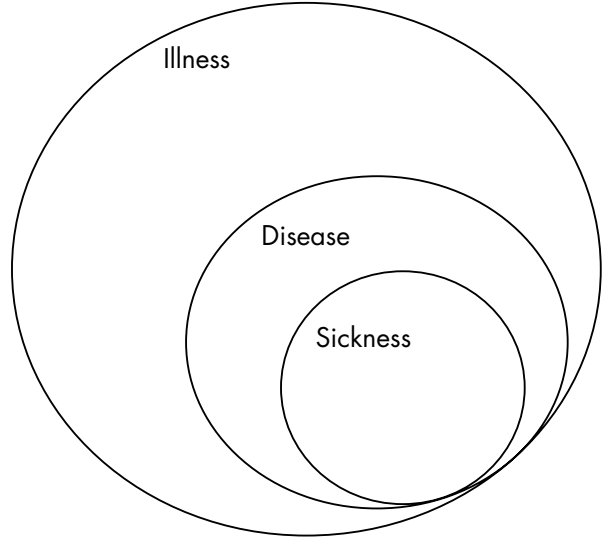

Figure 1 Hypothesised relation between illness, disease, and sickness absence, respectively.

Such more theoretical definitions are well in line with the results from different surveys in which lay persons are asked how they define health: actually most people do not see health only as a state where they are free of serious illness and disease. ${ }^{4} 920$

Even more complex are the concepts sickness and sickness absence. The possibility of doing a job or playing an important social part depends on the actual conditions in society, in the labour market, and in the person's abilities to cope with these conditions.

In some western nations, including Sweden, there have been large fluctuations in levels of sickness absence in the past decade. ${ }^{21}$ This has lead to questions of whether this is related to corresponding changes in illness and disease or whether it is the conditions of the labour market that vary, or something else.

The consequences of using different concepts and different types of data need to be further analysed. The aim of this study has been to study the relation and overlap between different measures of morbidity and health with the help of empirical data from the Swedish population. We are also trying to test to what extent different measures can substitute for each other as indicators when the aim is to identify time trends or differences between different population groups in the society.

\section{METHODS}

Annual survey and register data covering the working population in Sweden were used for the analyses.

The survey data used were from the yearly Swedish Survey on Living Conditions (ULF) made by Statistics Sweden, which includes many health related questions. A random sample of around 7000 people aged 16 to 84 who have been interviewed in their homes each year since 1974 is provided. Mostly new respondents are contacted each year. The drop out rate for the past 15 years is slightly over $20 \%{ }^{22}$ In this study data from the survey covering 1988 to 2001 were included for the sample of employed and self employed persons aged 16-65 (annual data for around 3500 persons). Because the questionnaires differed from year to year all years could not be included in some cases.

Register data from the National Social Security Board was obtained for the same people concerning the number of compensated sick leave days during that year. In Sweden all employed and self employed persons are entitled to sick leave benefits if their ability to work is reduced because of disease or injury. From 1994 to 2003 benefits for the first two weeks of a sick leave spell were paid by the employer, and not registered by the social insurance offices.

Registered sickness absence for more than 14 days has in most cases been used as a more robust measure. It is important to note that in Sweden there is no limit for duration of a sick leave spell.

In the ULF survey, the interviewers are specially trained for their task and used a well structured interview guide with standardised questions recurring each year.

Illness was operationalised with the help of the answers to a group of questions concerning different kinds of symptoms such as pain in neck, shoulder, back, hip, hands, elbows, knees, legs as well as questions about asthma and allergy. Persons reporting any such symptoms were considered to have an illness. Questions about sleeping disorders, fatigue, and anxiety were also used as a complement in some cases.

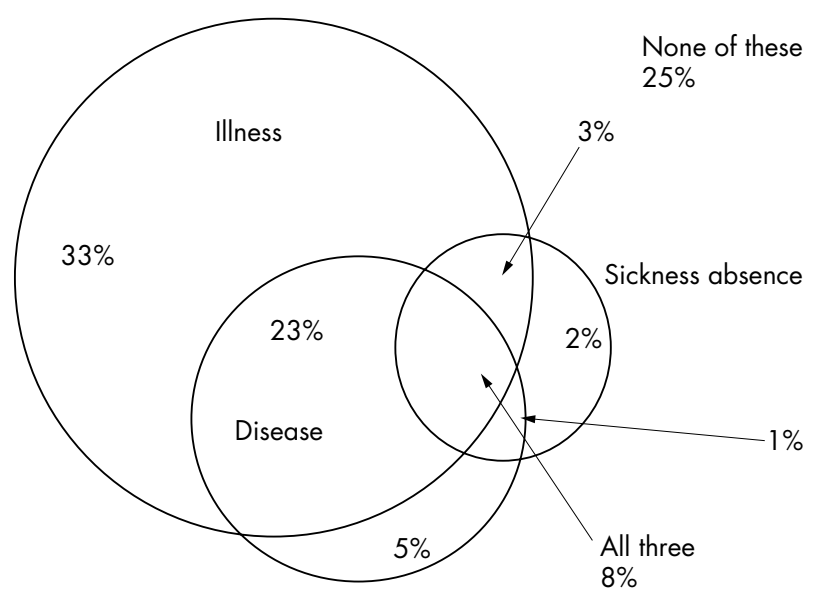

Figure 2 Relation between illness, disease, and sickness absence. Percentage of employed aged 16-64 in Sweden 1998-2001 $(n=13887)$.

Table 1 Social characteristics of those who reported illness, disease, or had been on sick leave (for two weeks or more) 1998-2001

\begin{tabular}{llllll}
\hline & Illness & Disease & $\begin{array}{l}\text { > 14 Sick } \\
\text { leave days }\end{array}$ & $\begin{array}{l}\text { Neither of } \\
\text { these }\end{array}$ & Number \\
\hline Total share in the employed population & 67 & 38 & 14 & 25 & 13887 \\
Share among women & 72 & 40 & 18 & 20 & 6770 \\
Share among men & 62 & 36 & 11 & 29 & 7117 \\
Share among those >55 years of age & 70 & 55 & 22 & 18 & 1934 \\
Share among blue collar workers & 72 & 40 & 18 & 20 & 5340 \\
Share among people with tertiary education & 60 & 33 & 11 & 31 & 4665 \\
Share among "poor" (with no possibility of & 74 & 45 & 20 & 18 & 1679 \\
getting 14000 SK in a week if needed) & & & & &
\end{tabular}

Data shown as percentages and numbers. The percentages are based on large samples and may only in worst cases deviate one or two per cent up and down because of sample reason. 


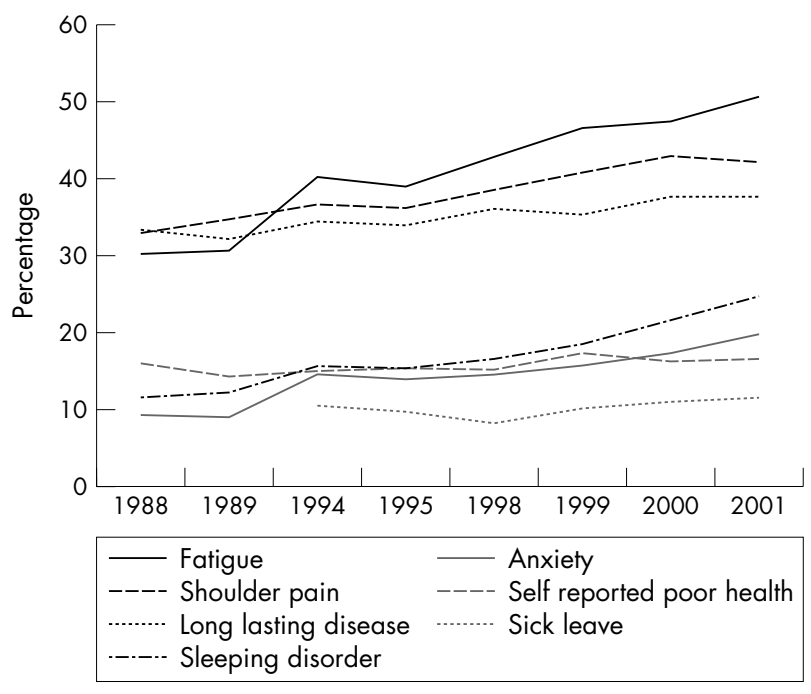

Figure 3 Indicators of morbidity and self reported health among employees in Sweden in 1988-2001. Age standardised ( $n=3500$ each year). Only more than 14 days of registered sickness absence are included.

For this study a person was considered to have a disease if they had been categorised with a diagnostic code according to ICD-9. ${ }^{23}$ To measure the existence of this the introductory question; "Have you any long lasting disease, trouble from a handicap, or any other weaknesses?" was given. In the case of a positive answer the respondent was asked to explain in more detail what the problems were, if they had visited a physician, been given a diagnosis, received medical treatment, or had a medical examination.

Self reported health was operationalised through the question: "In your opinion, how is your state of health? Is it very good, good, fairly, bad, very bad?" Those answering very good or good were considered perceiving their health to be good.

Most questions in ULF are tested in re-interview studies and in other methodological studies. Their reliability is well reported..$^{24}$

\section{Statistical analyses}

In the analyses data for different years were combined to calculate frequencies and overlap between the different measures and correlation coefficients. The accumulated effects of illness and disease on sickness absence were

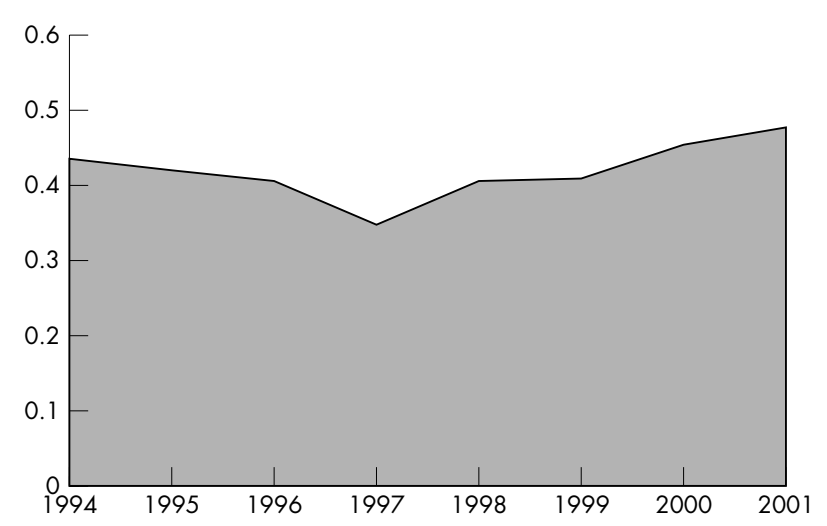

Figure 4 Relation between illness, disease, and sickness among employees in Sweden 1994-2001. Multiple correlation coefficients ( $n=3000$ each year). calculated for each year with the help of regression analysis, summed up as multiple correlation coefficients in a standard regression model with number of days as the dependent variable.

\section{RESULTS}

In the Swedish employed population aged 16-65, there were quite high numbers reporting morbidity according to the empirical definitions used. Table 1 presents the most current data.

- Almost $70 \%$ reported some kind of illness such as pain in different parts of the body, sleeping disorders, anxiety, or fatigue.

- About $40 \%$ had a long term disease in the sense that it was specified or diagnosed according to a diagnostic code. Some 15\% reported having more than one such disease.

- About one in seven in the working age population had had at least one sick leave spell of two weeks or more during the year when interviewed.

- About one in four had no illness, disease, or sickness according to the definitions used here.

- More than $80 \%$ reported their state of health as good or very good. Only $4 \%$ said they felt their health was very poor.

Considering social characteristics, similarities between the three definitions of ill health were found. Women had a higher share in all three categories of morbidity, but the difference was largest with respect to sickness absence. Older people, blue collar workers, and people with low incomes also had higher rates of morbidity in all three categories, while those with a university degree had a lower rate in all three.

When it comes to the degree of overlap between the three different aspects of morbidity no perfect fit is of course to be expected. Figure 2 gives a comprehensive picture of how weakly the different concepts were related to each other during the four years. Eight per cent of all respondents fell into all three groups of morbidity including general illness, disease, and a sick leave spell of two weeks or more. Twenty five per cent had none of these. In the other cases, the three groups were combined in various ways. (The correlation coefficients that could be calculated were highly significant but rather low). Figure 2 and table 1 illustrate how different kinds of health problems can be present without participants having to be sickness absent, how acute disorders do not always have to reflect a disease, and the fact that many people with long term diseases or disorders are not on sick leave, and so forth.

To scrutinise some of these differences in more detail we analysed how various aspects of morbidity have developed over time in Sweden. In figure 3, we follow some indicators of physical and mental ill health, as well as sick leave in the employed population between 1988 and 2001 (excluding 1990-1993 because of lack of data). Again, this figure creates a complex picture. There was a slight increase in the rate of persons with long term disease in the 15 years $(4.4 \pm 2.2 \%$

\section{What this paper adds}

The fact that illness, disease, and sickness absence have been found to be so different in terms of magnitude and development over time shows the need for a very careful use of different concepts and indicators. The comparatively low degree of overlap between them further shows that they represent different realities. 
between 1988 and 2001). Long term sickness absence increased only during the latest years. (Comparison is however difficult in this context because of the change in insurance terms especially before 1994). At the same time the incidence of shoulder pain increased more sharply $(9.3 \pm 2.2 \%)$. Above all, increasingly more people report fatigue $(20.1 \pm 2.2 \%)$ and sleeping disorders $(13.1 \pm 1.7 \%)$. In both of these latter cases, the frequency doubled over the years. Also the reporting of shoulder pain $(9.3 \pm 2.2 \%)$ and anxiety $(10.1 \pm 1.6 \%)$ increased. In contrast with these trends, however, the number of people reporting poor general health did not increase.

In figure 4 multiple correlation coefficients are presented from 1994 to 2001 . The result is based on multiple regression analyses with sickness absence as the dependent variable and pain in different parts of the body, sleeping disorder, fatigue, and anxiety as the independent variables. After 1997 disease and illness together seemed to explain increasingly more of the sickness absence for every year that passed. During the years before 1997, there was instead an opposite trend. The interrelation was greatest in the last year-2001 (although it was highly significant each year).

\section{DISCUSSION}

In the debate about health, ill health, sickness, and sickness absence there is often a confusing use of different concepts. These different concepts are often used as interchangeable alternatives, although they are based on very different conceptual and material prerequisites. Our purpose has been with the help of extensive population information to show the different pictures they actually give. We found that most people have some sort of illness or complaint. Fewer had been registered with some sort of disease. Even fewer had been on sick leave. The overlap between the categories was fairly low.

At the same time different concepts showed partly different trends over time. The share of people who report poor health has hardly changed at all, but there is an increase in the proportion that has complaints. This is particularly the case for shoulder pain, fatigue, and sleeping problems. The share reporting longlasting disease has grown slightly. The share of people on sick leave has risen.

Another result of this study was the fact that basically the same social differences could be found in all three dimensions of morbidity. Illness, disease, and sickness absence were related to occupational class, education, economic resources, and sex and age in about the same ways.

The fact that the different measures followed the same social dividing lines despite the large differences in levels in each indicator of morbidity may be seen as a sign that differences between the indicators are not systematically biased in relation to social characteristics. In other words this means that partially and crudely they reflect the same basic differences in society.

\section{Methodological considerations}

The source used was a big Swedish social survey (ULF), which means that most data were self reported, for example the diagnostic codes were based on information given by the participants themselves. None the less, data on diagnoses in

\section{Policy implications}

There is a need to further develop empirical knowledge about how different aspects of morbidity are interrelated and how differences could be interpreted in terms of causes and effects of ill health.
ULF is considered to have a comparatively high degree of reliability, in part because of the high quality achieved through a very thorough interview technique with the aid of numerous questions concerning complaints, disability, medical contacts, medication, handicaps, etc. Actually, this method might give more information than most other data sources. Also the diagnoses collected in this manner are very comprehensive compared with register data that often only cover a few specific categories.

Data on sickness absence from the National Social Security Board are considered very reliable. However, it is not optimal that our indicator of sickness absence is measured on an annual basis rather than a more delimited reference period as is the case for the survey data.

To explain sickness absence a regression model was used although the distribution of the absence (the dependent variable) was rather skewed. Other models and statistical procedures were however also tested (based on dichotomisation of the dependent variable and logistic regression). The overall picture seems always to be the same.

\section{Different indicators mean different things}

Although the different indicators for a number of reasons are not expected to be perfectly correlated, it is still surprising that the overlap is so low. The big discrepancies between the concepts imply that one has to be very careful with the use of different public health data.

Illness, disease, and sickness absence represent different aspects of morbidity and must be perceived as different phenomena. This also means that changes in one aspect need not correspond to changes in another. In other words, there is no necessary contradiction in the fact that some indicators of self reported general health in the Swedish population were comparatively stable in the 1990s, while the number who reported illness in the form of specific disorders, increased at the same time and that the share on sick leave rose since 1997.

There are a number of reasons why the different concepts of morbidity show different results. A first important fact, which has to be taken into consideration, is related to who defines a person's state of health, regarding among other things who has access to what kinds of knowledge. Is it the person who makes the definition, or is it decided by someone else, for example a physician?

A second important dimension concerns the severity of the condition in the sense of its consequences for the person. Some health problems can be seen as minor as they do not greatly affect the daily life of the person. Other health problems can be regarded as more severe as they limit the person more or less completely. Also important is whether the persons can learn to handle their problems, or perhaps learn to accept them as a natural part of their life situation.

A third important dimension is dealing with the temporal aspects of the health problem. Is it an acute state, a longlasting one, recurring, or even a chronic condition? A fourth dimension concerns the indirect consequences of a person's health condition. Does it cause social, economic, or other problems for the person regarding the role they normally have in society?

Concerning sickness absence the situation may for example have been, that weaknesses and health problems in the working age population produced more severe consequences during later years and underlying diseases became more problematic to handle at work because of changes in the labour market in terms of rising demands. ${ }^{26-28}$ People with minor illnesses may have been less able to attend work as the demands at work increased.

The weak multiple correlations between illness and disease on one hand and sickness absence on the other are of special 
interest. The ability to work despite an illness or a disease differs depending on type of work and work demands. This means that data on sickness absence tell us not only something about a person's illness but also about the job the person has, the demands and qualifications needed and possibilities that the person has to influence how to work and in what speed.

The multiple correlation also seems to change over time. Common sense often claims that with increasing numbers on sickness absence there must be a weaker connection to illness or disease. This is supposed to imply that people on sick leave are increasingly less sick when the numbers on sick leave goes up. The findings here however, point to an opposite interpretation. In the period when sickness absence was high in the population, the association with illness and disease was stronger, especially at the end of the period. In the middle of the 1990s, when sickness absence was lower, the correlation between the three indicators was also lower. Thus, after 1997 diseases taken together with illness seem to be the explanation for increasingly more of the sickness absence for every year that passes. It is also a well known fact that sickness absence (in, for example, Sweden) is related to the economic cycle and is low when the level of unemployment is high. The interpretation is said to be, that people with health problems, are more afraid to be away from work when the risk of losing the job is high.

In conclusion, the fact that illness, disease and sickness absence have been found to be so different in terms of magnitude and development over time shows the need for a very careful use of different concepts and indicators. The comparatively low degree of overlap between them further shows that they represent different realities. There is a need to further develop empirical knowledge about how different aspects of morbidity are interrelated and how differences could be interpreted in terms of causes and effects.

\section{Authors' affiliations}

A Wikman, S Marklund, Department of Work and Health, Swedish National Institute for Working Life, Stockholm, Sweden

K Alexanderson, Section of Personal Injury Prevention, Department of Clinical Neuroscience, Karolinska Institute, Stockholm, Sweden

Funding: none.

Conflicts of interest: none declared.

\section{REFERENCES}

1 Hensing G, Alexanderson K, Allebeck P, et al. How to measure sickness absence? Literature review and suggestions of five basic measures. Scand J Soc Med 1998;26:133-44.
2 Van-Poppel MN, de Vet HC, Koes BW, et al. Measuring sick leave: a comparision of self-reported data on sick leave and data from company records. Occup Med (Lond) 2002;52:485-90.

3 Bjorner JB. Self rated health. Stockholm: Swedish Council for Planning and Coordination of Research, 1996.

4 Eriksson I, Undén AL, Elofsson S. Self rated Health. Comparisons between three different measures. Int J Epidemiol 2001;30:326-33.

5 Undén AL, Elofsson S. Health from the patient's point of view. How does it relate to the physician's judgement? Fam Pract 2001;18:174-80.

6 Evans RG, Stoddart GL. Producing health, consuming health care. Soc Sci Med 1990;31:1347-63.

7 Rose G. Sick individuals and sick populations. Int J Epidemiol 1985;14:32-8.

8 Aggleton P. Health. London: Routledge, 1990.

9 Blaxter M. What is Health? In: Davey B, Gray A, Seale C, eds. Health and disease. Buckingham: The Open University Press, 1995.

10 Boorse C. Health as a theoretical concept. Philos Sci 1977:44:542-73.

11 Twaddle A, Nordenfelt L. Disease, illness and sickness: three central concepts in the theory of health. Linköping: University SHS, 1993.

12 Maslow A, Mittleman B. The meaning of healthy (normal) and of sick (abnormal). In: Caplan AL, Engelhardt HT, McCarney JJ, eds. Concepts of health and disease. Massachusetts: Addison-Wesley, 1981.

13 Last JM. A dictionary of epidemiology. New York: Oxford University Press, 1995.

14 Alexanderson K. Measuring health. Indicators for working women. In, Kilbom А, Messing K, Bild-Thorbjörnsson C, eds. Women's health at work Stockholm, National Institute for Working Life, 1998:121-61.

15 Alexanderson K. Sickness absence: a review of performed studies with focus on levels of exposure and theories utilized. Scand J Soc Med 1998;26:241-9.

16 Idler EL, Benyamini Y. Self-rated health and mortality: a review of twentyseven community studies. J Health Soc Behav 1997;38:21-37.

17 Marmot M, Feeney A, Shipley $M$, et al. Sickness absence as a measure of health status and functioning. J Epidemiol Community Health 1995;49:124-30.

18 Yeandle S, Macmillan R. The role of health in labour market detachment. In: Alcock P, ed. Work to welfare. Cambridge: Cambridge University Press, 2003.

19 Aronsson G, Gustafsson K, Dallner M. Sick but yet at work. An empirical study of sickness presenteeism. J Epidemiol Community Health 2000;54:502-9.

20 Medin J, Alexanderson K. Begreppen Hälsa och Hälsofrämiande-en litteraturstudie [The concepts of health and health promotion - a systematic literature review]. Lund: Studentlitteratur, 2000.

21 Lidwal U, Skogman-Thoursie P. Sickness absence in Sweden during the last decade. In: Marklund S, ed. Worklife and health in Sweden 2000. Stockholm: National Institute for Working Life, 2001:81-100.

22 SCB. Living conditions and inequality in Sweden-a 20-years perspective 1975-1995. Living condition report 91. Stockholm: Statistic Sweden, 1997.

23 WHO. The international classification of diseases (ICD 9) (http:// www.cdc.gov/nchs/about/major/dvs/icd9des.htm).

24 Wikman A, Wärneryd B. Measurement errors in survey questions: explaining response variability. Social Indicators Research 1990;22:199-212.

25 Thorslund M, Wärneryd B. Methodological research in the Swedish surveys of living conditions: problems of measurement and data collection. Social Indicators Research 1985; 16:77-95.

26 Wikman A. Labour Market Development in Sweden. In: Marklund S, ed. Worklife and health in Sweden 2000. Stockholm: National Institute for Working Life, 2001:21-34.

27 Eklund I, Englund A, Wikman A. Working conditions in Sweden and Europe. In: Marklund S, ed. Worklife and health in Sweden 2000. Stockholm: National Institute for Working Life, 2001:35-49.

28 vonOtter C. Swedish working life-searching for a new regime. Stockholm: National Institute for Working Life, 2004. 